\title{
A Review of Key Recent Studies on Effectiveness of Vocabulary Learning Tasks in L2
}

\author{
Alicia San-Mateo-Valdehíta \\ Universidad Nacional de Educación a Distancia (UNED)
}

Received: 30 March 2014 / Accepted: 19 January 2015

ISSN: $1697-7467$

\begin{abstract}
A review of the key empirical studies, published since 2001, in which the effectiveness of different vocabulary learning activities in L2, all including at least one writing exercise, is examined. The conclusion is that form-focused activities and those requiring a higher involvement load (Hulstijn and Laufer, 2001) or mental effort from learners, amongst which is writing, are the most effective in most experiments; while, on the other hand, fewer words are learned by reading.
\end{abstract}

Keywords: Vocabulary, form-focused activities, involvement load, writing, fill-in task, reading.

Revisión de los estudios recientes más relevantes sobre la efectividad de las tareas de aprendizaje de vocabulario en $L 2$

RESUMEN: Revisión de los trabajos empíricos más relevantes, publicados desde 2001, en los que se analiza la efectividad de diferentes actividades para el aprendizaje de vocabulario en L2, y que incluyen, al menos, un ejercicio de escritura. La conclusión es que las actividades centradas en la palabra en sí y las que requieren mayor nivel de participación (Hulstijn y Laufer, 2001) o esfuerzo mental por parte del aprendiz, entre las que se encuentra la escritura, son las más eficaces en la mayoría de los experimentos; frente a ellas, la lectura es con la que menos palabras se aprenden.

Palabras clave: Vocabulario, actividades centradas en la forma, nivel de participación o compromiso, escritura, ejercicios de huecos, lectura.

\section{INTRODUCTION}

Nowadays studies of teaching and learning vocabulary in second language (L2) still occupy, according to Carter and McCarthy (1988:VII), "the heart of language teaching and learning, in terms of the organization of syllabuses, the evaluation of learner performance, the provision of learning resources, and, most obviously, because it is how most learners see language and its learning difficulty". A few years after the first volume publication that Longman Publishing dedicated to teaching vocabulary, within the series Applied Linguistics and Language Study (which included the quote above), studies on vocabulary have definitely became "the guest of honor" in Applied Linguistics (Maiguashca, 1993:83), especially in English as L2 area. Bibliometric analysis by Meara $(2012 ; 2014)$ gives us an idea of the evolution of interest in this field and of who are the most established researchers. 
A center of interest is the study of activities that L2 learners carry out to incorporate new words into their mental lexicon, and the results they get from each of those activities. What is the source of learning vocabulary in L2? "Is it L2 input, enhanced input, interaction, communicative tasks, non-communicative 'artificial' exercises, list learning, or repetition?", Laufer wondered (2009:341). The purpose of these research projects is eminently practical: it is to verify what the most efficient way to increase vocabulary is and these results will impact on teaching techniques and learning materials.

Our purpose here is to review and make an analysis of empirical studies published since 2001 where the effect that different activities produce in vocabulary learning in L2, mainly English and Spanish is analized, with the aim of checking whether there is an agreement on the most effective type of exercise. The common feature of all the studies we present here is that at least one productive activity such as writing, either sentences or longer texts where you need to insert the word you want to learn is used, and this activity is compared with other diverse activities.

The most recent approaches emphasize, firstly, the importance of the involvement load or the mental effort made by learners which each task requires; and, secondly, the importance of the activities which are focused on the words themselves (form-focused activities), compared to those in which attention is directed towards message content (focus on meaning).

We have traced an extensive bibliography in order to collect key empirical studies, although we are aware of the impossibility of including all experiments performed with learners of any other L2 or those which are under development right now.

From studies on learning vocabulary in L2, carried out since the early twentieth century until the eighties, Nation (1982) conducted a review in which he classified them around key words such as direct and indirect learning, or receptive and productive learning, to be addressed in future research.

In a later work, Laufer (2009) made a chronology, beginning with Nation's review (1982). She collected articles about vocabulary learning in L2 based on input and on form-focused instruction, as well as on theoretical proposals. Our paper completes this work, because it extends to the present and to the field of Spanish as L2; although it is limited to empirical research projects, of which we give a detailed explanation. It should be added that we will not post results of research on learner personal variables, such as L1, age, attitude towards the language or motivation.

Now we will present the analyzed studies divided into two sections: in the first ( $§ 2.1$ ), we will focus on those that include any activity based on reading and which is compared at least with a writing exercise, either the writing of disconnected sentences or a composition; the next section $(\S 2.2)$ will be dedicated to experiments contrasting exclusively writing activities. And in the third section ( $§ 3)$, we will discuss conclusions drawn from the analysis.

\section{Comparative Studies of Activities with Different Involvement Load And Form-Focused or Focused on Meaning}

According to the involvement load hypothesis (Hulstijn and Laufer, 2001:539-558), the incorporation of new lexical items to the mental lexicon depends on three basic components that can be graded and which are associated with the activity learners perform. Those 
components are need, search, and evaluation. The need component is the non-cognitive dimension that provides motivation. If it is imposed by an external agent or by the task, we say it is a moderate need; this is the case, for example, of reading comprehension exercises that require prior knowledge of certain vocabulary or in which the teacher asks students to write a sentence using a specific word. Need is strong when it is self-imposed by learners; for example, if they decide to look up a word in the dictionary while they are preparing an oral presentation.

Search occurs when students make the effort to find the meaning of an unfamiliar word in the L2 or to find the word in the L2 that expresses the concept they want to use, and which is known in the L1, by consulting a dictionary or asking the teacher. There is no search if, for example, a text is accompanied by marginal notes in which new words are glossed.

Evaluation involves making any decision about whether a word or one of its meanings fits in a given context. It is a moderate evaluation if the task is to recognize differences between several words (such as in fill-in activities), or between several senses of a lexical unit in a given context. Evaluation is referred to as strong when it is required to make a decision about how a new word is combined with others in learner-generated context.

The combination of these three factors (need, search, and evaluation) gives us the degree of involvement load (or mental effort) that a task requires, and the greater the involvement load is, the easier it is for learners to incorporate the new item into their mental lexicon.

So, if we consider involvement load scale, writing production activities in which an appropriate context for a given stimulus word is created, induce a moderate need and strong evaluation; and if learners receive a list of words with their definitions, there is no search.

On the other hand, activities can be classified depending on where learners have to focus. When they have to focus on the message, it is a focus on meaning task, such as reading a text without any further activity. This is a methodology widely used, through which it is expected or required that students will develop their vocabulary knowledge, and, as we shall see, apparently in L2 it does not appear to be as effective as supposedly it is in the L1. Instead, specifically vocabulary exercises can either focus on word form to perform a (more or less) communicative task (focus on form, FonF) when, for example, learners are reading a text and they look up unknown words in order to understand the text; or such exercises can also direct learner's attention to lexical units in a non-communicative task (focus on forms, FonFs); for example, when students receive a list of words in L2 with their translation to L1, without a context, and they must complete a series of disconnected sentences using the given words, or they should match words to their definitions or create an appropriate context for them. Now we will see the effect of tasks with different involvement load and focusing on one of the above aspects, in order to verify the relationship between these factors, and learning and retention of vocabulary in L2.

\subsection{Studies of writing and reading activities}

In the following experiments the effectiveness of writing a composition (Hulstijn and Laufer, 2001; Kim, 2008; Laufer, 2003) or writing original sentences (Agustín Llach, 2009; Browne, 2003; Keating, 2008; Laufer, 2001; 2003; Pichette, De Serres and Lafontaine, 2012; Webb, 2005) is compared with reading comprehension activities (Agustín Llach, 2009; Hulstijn and Laufer, 2001; Keating, 2008; Kim, 2008; Laufer, 2001; 2003), fill-in gaps within a text 
(Hulstijn and Laufer, 2001; Keating, 2008; Kim, 2008) or in disconnected sentences, where target words have been deleted (Laufer, 2001; 2003); or with other activities like crossword puzzles (Browne, 2003), or extensive reading without any extra assignment (Browne, 2003; Pichette, De Serres and Lafontaine, 2012; Webb, 2005).

Hulstijn and Laufer conducted a research project in the Netherlands and Israel, respectively, with adult learners of English as L2. First, they implemented a parallel experiment (Hulstijn and Laufer, 2001) in both countries, using the same methodology and similar participants (186 advanced university learners of English as L2: 87 in Holland, and 99 in Israel), in order to be able to compare their results. Three types of tasks were used as a pre-test: (1) answering ten reading comprehension questions about a text in which the ten target expressions or words are highlighted in bold print and glossed in L1 in the margin of the text; (2) answering ten reading comprehension questions about a text in which the ten target words have been deleted, and filling in the ten gaps with the missing words from a given list of 15 words; and (3) writing a letter and incorporating the target words that are listed with their definition and an example in the L2, and the equivalent in the L1.

Results were measured with two tests (post-tests) students received after the task (pretest); the first one right immediately after the task, and the delayed post-test was done one week later in the Netherlands, and two weeks later in Israel. Students had to translate target words into their L1 or give an English explanation for those words. Both in Israel and in the Netherlands performance in the writing group (3) was higher than that in the reading comprehension plus fill-in group (2), which was higher than that in the reading comprehension group (1). The difference between the results of the writing group and the other two was statistically significant.

Keating (2008) replicated Hulstijn and Laufer's study to verify, among other things, whether results were similar with 79 university beginner learners of Spanish as L2. In this case, the researcher used pseudowords created following phonological and morphological parameters of Spanish, rather than low-frequency words; and the third task was writing original sentences instead of a letter. In the post-test he also introduced a modification: after the passive recall post-test of translating target words into the L1, participants were asked to translate eight English sentences, which contained target words into Spanish (L2); this is an active or productive recall post-test. In immediate and delayed passive (or receptive) recall post-tests retention was highest in the writing group (3); but in the delayed productive recall post-test, retention was highest in the reading comprehension plus fill-in group (2). One explanation for this decline in knowledge could be that students did not use the target words and were not exposed to them during the two-week interval between tests.

Kim (2008) conducted another experiment which was a partial replication study of Hulstijn and Laufer (2001). There were 64 participants from 27 different countries, English as L2 students with different levels of the L2 (34 undergraduates and 30 enrolled in an intensive course). Learning tasks were the same, but the post-test was changed. As 19 different languages were represented, participants were not asked to translate target words into their L1; instead Paribakht and Wesche's (1993) Vocabulary Knowledge Scale (VKS) was used, which combines participants' perception about their word knowledge and how they show it. Statistical analysis of scores obtained in both recall post-tests (immediate post-test and delayed post-test, two weeks later) revealed results were significantly better in the composition group (writing group) (3), than in the reading comprehension and fill-in group (2), and in the reading comprehension group (1). 
Laufer (2001; 2003), in the meanwhile, carried out several experiments with high school and university students of English as L2, in which she compared the effectiveness of reading and reading comprehension (including using the dictionary) exercises, and of decontextualised word-focused activities, that consisted of filling in sentences with target words, and writing original sentences or longer texts using them. In all these studies, after training activities, participants received an unexpected post-test in which they had to write the meaning (in the L1 or L2) for target words; and two weeks later, the same post-test was repeated. Again the reading group got lower scores; which verifies the effectiveness of word-focused tasks against reading comprehension activities. Laufer (2001:52) suggests reading is not the main, nor the best, source of vocabulary learning in the L2, where word-focused tasks are essential in building and broadening the learner's mental lexicon; nevertheless reading could be useful to expose learners to words for the first time, to expand knowledge of already known words, or to reinforce memory of words in the process of being learned (Laufer, 2003:583-584).

Agustín Llach (2009) also compared the effectiveness of reading and writing activities to vocabulary gains in L2. The participants were 27 high-intermediate level learners of Spanish as L2, who were enrolled in the last year of high school in Germany. She used these three tasks: (1) reading a text and answering three multiple choice reading comprehension questions; (2) reading a glossed text and answering ten multiple choice reading comprehension questions, which are related to the ten target words explained in the margin; (3) writing ten sentences with the target words given in a bilingual Spanish-German list.

The post-test consisted of two questionnaires: firstly, a test of productive vocabulary knowledge, where ten words given in German had to be translated into Spanish; secondly, a test of receptive vocabulary knowledge, where participants had to provide the German translation of the target words given in Spanish. Three weeks later, the post-test was repeated.

Scores suggested participants who had to read the non-glossed text and answer the three comprehension questions (task 1) obtained the lowest scores in all the tests; and "[...] learners who were required to complete the FonFs activity [task 3] manage to recall (productive knowledge) and recognize (receptive knowledge) the highest number of words when tested immediately afterwards and also three weeks after the activity" (Agustín Llach, 2009:16), but the results for delayed testing were not significant.

Browne (2003) turned the reading comprehension activity into an extensive reading task and he compared it with two word-focused exercises: the first was vocabulary tasks such as crossword puzzles, matching activities, and word searches; and, the second was writing two complete sentences using each of the ten given words, which are low frequency words. In addition to the list of words with accompanying definitions, one of the two writing groups was given a sentence exemplifying usage of each word. The participants were 109 Japanese university students of English as L2, whose major was Business Administration. To establish short term vocabulary retention, after learning activities, a multiple choice post-test was completed. Statistical analysis of post-test results indicated that significantly fewer words were incorporated into the learner mental lexicon with the reading activity. This reading text had been modified so that target words appeared twice or three times and were underlined to draw them to the readers' attention. The conclusion was that significantly more words were learned by the students in the writing group which did the exercise without the example usage sentences, and by word manipulation tasks, such as crossword puzzles, matching activities, and word searches. 
Webb (2005) studied the effect of a receptive activity such as reading sentences that included the target words: here learners had to observe different contexts in which pseudowords were used in order to memorize them; and, on the other hand, the effect of a productive activity such as writing sentences. He carried out an initial pilot study, and in a second study he controlled variables which initially were not taken into account and which could have affected the scores obtained. In the final project, 49 intermediate level Japanese university students of English participated, and it was shown that the writing activity was significantly more effective both in productive and receptive post-test sections, in which knowledge of orthography, meaning, association, syntax, grammatical functions, and form of each word were measured. Webb (2005:50) says: "productive learning is superior to receptive learning not only in developing productive knowledge but also in producing larger gains in receptive knowledge".

Pichette, De Serres and Lafontaine (2012) conducted a study using the same tasks as Webb (2005) and they obtained similar results. In this case, participants were 203 Frenchspeaking Canadian university students with intermediate and advanced L2 levels of English. There were two activities (in each, eight low frequency target words were included): for the reading task learners had to read three sentences containing each target word in three different syntactic functions (subject, direct object, and indirect object); for the writing task, they had to write three sentences containing each target word. Each item was preceded by the target word and its definition in the L1 (French). In the post-test, participants had to provide L2 words beside L1 French definitions. A week later the same test was administered. Statistical analysis showed that in the immediate recall post-test the average number of correct words included in the writing activity was significantly higher than words practised in the reading activity.

\subsection{Studies of writing activities}

So far all these experiments we have discussed here compare working with a reading task to writing exercises. Now we will focus on research projects that compare only writing activities, in particular, writing sentences activity is compared with copying a word along with its definition or correct sentence (which is actually a selection task) (San-Mateo Valdehíta, 2012), filling-in activities (Folse, 2006), writing a longer text (Kim, 2008), translating sentences into the L2 (Kondo, 2007) or writing down the target word (Barcroft, 2004).

After conducting a pilot study to ratify variables and methodology (San-Mateo-Valdehíta and Andión Herrero, 2012), San-Mateo-Valdehíta (2012) implemented an experiment with 150 B1 level students of Spanish from a United States university, in order to determine which of these three focus on forms tasks (FonFs) was the most effective: (1) writing the target word (in this case, pseudowords) next to its definition, (2) writing the target word next to the sentence that includes its semantic equivalent, and (3) answering a question by writing a sentence containing the target word.

After the training activity in which each group practised with a different task, a post-test including the three tasks was provided to participants in order to check which one helped them remember more words, and what each task equipped them to do. Analysis of results indicated, first of all, that all training activities had been very effective, since the average rate was 8.16 out of 10 ; and, secondly, that sentence writing was the best exercise to enlar- 
ge mental lexicon, and definition selection was the least effective task; and the difference between these activities was significant (San-Mateo-Valdehíta, 2013b). On the other hand, when analyzing results obtained in each of the three post-test sections, where participants practised with a different task, it was found that learners who had trained by writing sentences got higher scores in all three post-test sections; and, instead, those participants who had practised with definitions got the lowest score (San-Mateo-Valdehíta, 2013a:19-23). The conclusion was that the productive activity enabled learners to use new words in speech (productive task) and also to recognize them (receptive task).

Folse (2006) focused his study on the effect of fill-in activity and sentence writing activities; and he added to the first task a modification to compare exercises that required more or less time. So the tasks were these three: (1) completing one fill-in exercise of five sentences with one of six given words; (2) completing three fill-in exercises as in (1); and (3) writing original sentences including given words. The participants were 154 students of English as L2, including 14 different first languages; they were attending intensive courses at four US universities; and their proficiency levels ranged from lower intermediate to advanced level. All subjects practised the three activities and the 15 target words (in this case, 15 low frequency verbs). Immediately after the learning activities, participants were given the posttest to measure their word knowledge thanks to this scale: (1) they do not know what the word means; (2) they know what the word means, so they are able to provide an English synonym or a translation in their L1; (3) they can use the word in an original sentence.

Results indicated that three fill-in activities were significantly more effective than the other two tasks; but the difference between one fill-in exercise and original sentence writing activity was not statistically significant. Folse (2006:287) says:

The current study indicates that doing multiple target word retrievals in an exercise, no matter how superficial the exercise may seem, is a stronger and more facilitative factor in L2 vocabulary learning than the purported deeper processing or involvement load that writing original sentences with new L2 vocabulary may offer.

As the results obtained with (1) the fill-in exercise and (3) sentence writing task were not significantly different, we cannot conclude that the first activity is much more effective than the third.

Folse (2006:288) claims sentence writing tasks require a lot of time for both the student and the teacher-corrector; however, fill-in exercises can be prepared and corrected easily and quickly. Despite these "shortcomings" Folse states, in the post-test he used a sentence writing activity as the way to check whether participants learned target words.

Kim (2008) implemented an experiment with 40 young adult English as L2 learners, from nine countries, who spoke 18 different L1s. The aim was to check whether two activities that required the same theoretical mental effort or involvement load (Hulstijn and Laufer, 2001), such as the writing of original sentences or a composition, using in both cases the given target words, had the same effect on the immediate incorporation (initial vocabulary learning) of new words into the mental lexicon and also on their retention: "According to the involvement load hypothesis, two tasks that induce the same amount of involvement should promote similar results of vocabulary acquisition" (Kim, 2008:304).

In order to measure vocabulary knowledge, an adaptation of the Vocabulary Knowledge Scale (VKS) (Paribakht and Wesche, 1993) was used in the post-tests; the first one was conducted immediately after the learning task and the delayed post-test, two weeks later. The 
analysis of results indicated the difference between the two tasks (composition and sentence writing) involving a moderate need, no search, and strong evaluation (Kim, 2008:310) was not significant; so these activities were both equally effective in increasing vocabulary in L2.

Kondo (2007) introduced a new activity, namely translation from L1 into L2. He carried out an experiment with 63 Japanese university students of English as L2, from lower intermediate to upper intermediate levels of proficiency. The goal of this study was to compare the effect of two tasks with different levels of semantic elaboration; these activities are: (1) writing sentences with 14 target words, which are low frequency words; and (2) translating Japanese sentences into English equivalents using the 14 target words. The first activity requires learners to think of a suitable context for the target word and to write a meaningful sentence containing the word. The translation activity, however, requires participants to translate into English mechanically the given sentence using one of the given words (Kondo, 2007:73). Thus these activities differ in the degree of required semantic elaboration, which is higher in the former task.

The analysis of the results indicated that the scores of the sentence-writing group were significantly better on the three post-tests, the first one being conducted immediately after the learning task, then one week after, and the third post-test, three weeks after the activity.

If the activities of Kondo's (2007) experiments fostered retention of word meaning, now we will analyse tasks that focus on word form itself. Barcroft (2004) performed numerous experiments with learners of Spanish as L2 in order to confirm his hypothesis about the strong negative effects on learning word form that the semantic elaboration that writing sentences including target words required.

In the first study, 44 elementary level students of Spanish as L2 had to learn 24 low frequency concrete nouns, by two tasks: (1) the participants viewed four repetitions of each word and the image of the represented object while attempting to learn the word; and (2) they viewed just one repetition of each word and its image representation, and they were asked to write a sentence in Spanish including the target word. After the exposure phase, three equal post-tests were given: one immediately after the task, another two days after the learning activity, and the third post-test, a week later. Participants were asked to write down the Spanish word for each image they saw.

Post-tests score was done according to a Lexical Production Scoring Protocol (LPSPwritten) (Barcroft, 2003:555; 561), which rated the number of letters and syllables of each word that learners were able to produce and correctly place within target words, besides whole words. Results indicated, in the three post-tests, that informants who wrote sentences recalled fewer syllables and whole words, and that score difference was statistically significant.

Then, in a second study, the participants were 10 elementary level students of Spanish as L2. Barcroft (2004) eliminated the difference in the number of exposures and exposure time to the target words in order to "examine whether the effects observed for sentence writing were due to differences in presentation patterns in that study" (Barcroft, 2004:320). Nevertheless, the conclusion was the same: students who did not write sentences in the learning phase retained more letters, syllables, and words; although only the difference between letter and syllable retention was statistically significant.

In several subsequent experiments, Barcroft $(2006 ; 2007)$ took to an extreme his hypothesis of the negative effect of writing and compared the influence of the writing of target words or one of their syllables with viewing word-picture pairs. His conclusion was that some 
of negative effects observed in previous studies came from writing (copying) target words (within a sentence, in these cases); and he also concluded that writing a single fragment of each target word was less effective because it "diverted the attention of learners even further than did writing an entire word during L2 vocabulary learning" (Barcroft, 2007:723).

Undoubtedly the most problematic issue of Barcroft experiments is the scoring system, whereby, for example, writing a letter included in the target word scores 0.25 (it would be very easy to get these points in Spanish by typing the letter $a$ ); writing emb..., ...udo, ...bud... or funudo instead of embudo (funnel, in English) scores 0.75 ; or writing em..., ...do or ...bu instead of embudo, or writing cemimbavillo instead of cabestrillo (sling, in English) scores 0.5 points (Barcroft, 2003:555; 561). We suspect that this allocation of points could distort results and hide real retention of words. At the same time, in some of these experiments the number of participants was very small and all of them were elementary level learners. In any case, it draws our attention to the ineffectiveness of learning tasks: in the first two experiments, participants failed to remember as many as 3 words (2.75 and 2.1, to be exact) out of 12 .

\section{Conclusions}

The conclusion from the analysis of all these experiments is that the productive task of writing sentences or writing a text along with different types of activities is, in most cases, the most effective task to help L2 speaker to learn and retain new words in their mental lexicon, regardless of the L2 and learner level (Agustín Llach, 2009; Browne, 2003; Hulstijn and Laufer, 2001; Keating, 2008; Kim, 2008; Kondo, 2007; Laufer 2001; 2003; Pichette, De Serres and Lafontaine, 2012; San-Mateo-Valdehíta, 2012; Webb, 2005). However, some studies have come to a different conclusion: Barcroft (2004) and Folse (2006). To Barcroft, not only do productive activities not help students to learn new words, but they make it more difficult, because these tasks require semantic processing which consumes resources that could have been used to process formal properties of the lexical unit. However, productive activities can facilitate the retention of familiar words. Barcroft refers specifically to learning word forms, but not meanings. Thus it may be that one kind of activity does not diminish the other; as Kondo (2007:75) says:

It is obvious that semantic elaboration does not promote learning of word form but does promote understanding of meaning. The negative effect on word form learning does not diminish the value of sentence writing as a useful way of learning the semantic aspect of vocabulary.

Anyway, as already stated, Barcroft's (2003) scoring system is, at least, suspect, because of the score awarded for recalling just one of the letters included in the target word, for example. On the other hand, in Folse's (2006) studies, the comparison of the activities may be unsuitable since he compares an exercise in which three exposures to the target word occurred with another task in which only one happened.

The results of most studies support the involvement load hypothesis (Hulstijn and Laufer, 2001): writing is an activity that requires strong evaluation and moderate need, versus fill-in exercises that require moderate evaluation and moderate need, or reading comprehension 
tasks that require only moderate need (and if a dictionary is used, also search). Ultimately, only creating a context in which target words can be inserted needs strong evaluation, and it is the task that requires most mental effort of the learner. Browne (2003:64-65) adds that even if learners make mistakes in their written compositions, the effort still has its reward.

Furthermore, we found that focus on meaning activities, such as reading comprehension tasks or just reading a text, are less successful compared to focus on word form activities, such as answering questions about word meaning (Agustín Llach, 2009), filling the blanks in sentences or in a text using the given words (Hulstijn and Laufer, 2001; Keating, 2008; Kim, 2008; Laufer, 2001; 2003); or crossword puzzles and matching word-meaning activities (Browne, 2003), and, above all, creating a context in which given lexical items are used (Agustín Llach, 2009; Browne, 2003; Hulstijn and Laufer, 2001; Keating, 2008; Kim, 2008; Laufer, 2001; 2003; Pichette, De Serres and Lafontaine, 2012; Webb, 2005). According to Agustín Llach (2009:20), presenting words in isolation following by manipulation exercises without any proper communicative aim is particularly effective in incorporating new words into the mental lexicon, although it is not the only way.

In short, we believe that the number of studies reviewed here is enough to say that a productive activity such as writing, which requires a high level of involvement (or mental effort) from L2 learners, is considerably more effective in learning new words than other activities that require a lower level of involvement. However, discordant results lead us to consider the need for further research on the effect of different tasks on vocabulary retention and also of broadening the type of exercises to discover which is most efficient, and if there are different degrees of effectiveness depending on factors such as the L2 proficiency level, for example.

Finally, we also would like to point out that this literature review has a clear practical application for teaching techniques and learning materials. All kinds of tasks which focus on learning words should be proposed in order to facilitate learning vocabulary in L2, and productive activities such as writing should also be incorporated; although they require more mental effort, they are very effective, as has been demonstrated in numerous studies, and as Laufer recommends it is important to follow this principle,

1. Do not rely too much on uninstructed acquisition. Picking up words from context has limitations, unless learners are flooded with input. When the main source of vocabulary is classroom learning, enhance it by form-focuses instruction such as the explanation and study of words both in lists and in contexts of various lengths (Laufer, Meara and Nation, 2005:3).

\section{Acknowledgements}

I thank Jim Lawley for helping me with the English version of the manuscript.

\section{REFERENCES}

Agustín Llach, M. P. (2009). "The effect of reading only, reading and comprehension, and sentence writing in lexical learning in a foreign language: some preliminary results", in Revista Española de Lingüística Aplicada, 22: 9-33. 
Barcroft, J. (2003). "Effects of questions about word meaning during L2 Spanish lexical learning", in The Modern Language Journal, 87, 4: 546-61.

Barcroft, J. (2004). "Effects of sentence writing in second language lexical acquisition", in Second Language Research, 20, 4: 303-34.

Barcroft, J. (2006). "Can writing a new word detract from learning it? More negative effects of forced output during vocabulary learning", in Second Language Research, 22, 4: 487-97.

Barcroft, J. (2007). "Effects of word and fragment writing during L2 vocabulary learning", in Foreign Language Annals, 40, 4: 713-26.

Browne, C. (2003). Vocabulary acquisition through reading, writing and tasks: a comparison. Unpublished doctoral thesis. Tokio: Temple University Japan.

Carter, R. and McCarthy, M. (eds.) (1988). Vocabulary and language teaching. Londres: Longman.

Folse, K.S. (2006). "The effect of type of written exercise on L2 vocabulary retention", in TESOL Quarterly, 40, 2: 273-93.

Hulstijn, J.H. and Laufer, B. (2001). "Some empirical evidence for the Involvement Load Hypothesis in vocabulary acquisition", in Language Learning, 51, 3: 539-58.

Keating, G.D. (2008). "Task effectiveness and word learning in a second language: the Involvement Load Hypothesis on trial", in Language Teaching Research, 12, 3: 365-86.

Kim, Y. (2008). "The role of task-induced involvement and learner proficiency in L2 vocabulary acquisition", in Language Learning, 58, 2: 285-325.

Kondo, H. (2007). "The effects of semantic elaboration on L2 vocabulary learning", in Research Journal of Jin-Ai University, 6: 71-78.

Laufer, B. (2001). "Reading, word-focused activities and incidental vocabulary acquisition in a second language", in Prospect, 16, 3: 44-54.

Laufer, B. (2003). "Vocabulary acquisition in a second language: Do learners really acquire most vocabulary by reading? Some empirical evidence", in The Canadian Modern Language Review, 59, 4: 567-87.

Laufer, B. (2009). "Second language vocabulary acquisition from language input and from formfocused activities", in Language teaching, 42, 3: 341-54.

Laufer, B., Meara, P. and Nation, I.S.P. (2005). "Ten best ideas for teaching vocabulary", in The language teacher, 29, 7: 3-6.

Maiguashca, R.U. (1993). "Teaching and learning vocabulary in a second language: past, present, and future directions", in The Canadian Modern Language Review, 50, 1: 83-100.

Meara, P.M. (2012). "The bibliometrics of vocabulary acquisition: an exploratory study", in Regional English Language Centre Journal, 43, 1: 7-22.

Meara, P.M. (2014). "Vocabulary research in The Modern Language Journal: A bibliometric analysis", in Vocabulary Learning and Instruction. Advance online publication. Doi: 10.7820/vli.v03.1.meara. Available from: http://vli-journal.org/wp/vli-v03-1-meara/, accessed 1 April, 2015.

Nation, I.S.P. (1982). "Beginning to learn foreign vocabulary: A review of the research", in Regional English Language Centre Journal, 13, 1: 14-36.

Paribakht, T.S. and Wesche, M.B. (1993). "Reading comprehension and second language development in a comprehension-based ESL program", in TESL Canada journal, 11, 1: 9-29.

Pichette, F., De Serres, L. and Lafontaine, M. (2012). "Sentence reading and writing for second language vocabulary acquisition", in Applied Linguistics, 33, 1: 66-82.

San-Mateo-Valdehíta, A. (2012). Aprendizaje de léxico en español como segunda lengua/lengua extranjera: investigación sobre la efectividad de tres tipos de actividades para aprender vocabulario. Unpublished doctoral thesis. Madrid: UNED. 
San-Mateo-Valdehíta, A. (2013a). "El conocimiento productivo y receptivo del vocabulario en L2: Análisis de la efectividad de tareas de reconocimiento y de producción", in Revista Nebrija de Lingüística Aplicada a la Enseñanza de Lenguas, 14: 13-29. Available from: http://www.nebrija.com/revista-linguistica/el-conocimiento-productivo-y-receptivo-delvocabulario-en-12, accessed 1 April, 2015.

San-Mateo-Valdehíta, A. (2013b). "El efecto de tres actividades centradas en las formas (Focus on form $S$, FonFs): la selección de definiciones, la selección de ejemplos y la escritura de oraciones, en el aprendizaje de vocabulario en segundas lenguas", in RceL-Revista Electrónica de Lingüistica Aplicada, 12: 17-36. Available from: http://dialnet.unirioja.es/ descarga/articulo/4648292.pdf, accessed 1 April, 2015.

San-Mateo-Valdehíta, A. and Andión Herrero, M.A. (2012). "Planteamiento de un proyecto de incorporación léxica en español lengua meta. Cuestiones metodológicas y estudio piloto", in EPOS, XXVIII: 73-90.

Webb, S. (2005). "Receptive and productive vocabulary learning: The effects of reading and writing on word knowledge", in Studies in Second Language Acquisition, 27, 1: 33-52. 